УДК 336.018

DOI: $10.17223 / 22229388 / 18 / 2$

\section{E.B. Гариуева}

\section{КОНЦЕПЦИЯ «ЧЕЛОВЕЧЕСКИЙ КАПИТАЛ» - ОСНОВА СОДЕРЖАНИЯ БАЗОВОГО АКТИВА ДОМОХОЗЯИНА}

Рассмотрень образование как составная часть человеческого капитала, а также прочесс инвестирования домохозяйствами в свое образование и влияние осуществленных инвестиций на будущие доходы домохозяйств.

Ключевые слова: финансы домохозяйств; человеческий капитал, базовый актив, доходы домохозяйств.

В экономической теории термин «домашнее хозяйство» (домохозяйство) трактуется как хозяйственная единица, состоящая из одного или более лиц, объединяемых общим бюджетом и местом проживания, которая снабжает экономику ресурсами и использует полученные за них деньги для приобретения товаров и услуг, удовлетворяющих материальные потребности человека [1. С. 14; 2].

Образование как составная часть человеческого капитала относится к «Базовому активу» домашнего хозяйства [3. С. 230, 251]. Финансирование как вложение ресурсов и финансовых средств есть предваряющая производство стадия формирования человеческого капитала, а все виды деятельности, способствующие накоплению человеческого капитала, - это уже непосредственный процесс его производства, т.е. следующая стадия в рамках более общего процесса оборота человеческого капитала. Заметим, что следующей стадией будет уже его производительное использование (потребление).

Концепция «человеческого капитала» в ее современном виде явилась закономерным результатом генезиса мировой экономической и философской мысли. С тех пор как человечество стало осознавать свою творческую производительную роль, свое значение по преобразованию окружающего мира, а производство жизненных условий и материальных благ выделилось в самостоятельную сферу под названием «экономика», наиболее пытливые умы пытались познать тайну творческой силы человека, выявить ее наиболее характерные качества и свойства, оценить, измерить и дать количественную интерпретацию.
В 1970-е гг. Г. Беккер сформулировал простую и по сути универсальную модель распределения личных доходов. Для этого он обратился к аппарату кривых спроса и предложения инвестиций в человеческий капитал. Построение кривых спроса и предложения инвестиций в человеческий капитал позволило Беккеру не только выявить сходство процессов инвестирования в любой вид капитала, будь то физический или человеческий, но и продемонстрировать особенности последнего, в частности, его социальную природу [4].

Предложенная Г. Беккером модель охватывает неравенство доходов не только от инвестиций в человеческий капитал, но и от собственности (от полученных в дар или по наследству иных активов). Отдача от вложений в человека в среднем много выше, чем от вложений в физический капитал. Однако в первом случае она убывает с ростом объема инвестиций, тогда как в отношении иных активов (недвижимость, ценные бумаги, банковские депозиты и т.п.) уменьшается мало или вообще не меняется. Отсюда вытекает оптимальная стратегия рациональных семей: сначала инвестировать в человеческий капитал детей, в их общую подготовку, поскольку отдача от этого сравнительно выше, а затем, когда по мере убывания она сравняется с нормой доходности прочих активов, переключаться на инвестирование в них, с тем чтобы впоследствии передать их детям в наследство или в дар. Исходя из этого, Беккер установил важную закономерность: семьи, оставляющие наследство, осуществляют оптимальный размер инвестиций в человеческий капитал детей, тогда как семьи, наследства не оставляющие, по большей части недоинвестируют в их образование.

Итак, производство человеческого капитала процесс создания производительных способностей человека посредством инвестиций в специфические процессы деятельности индивидуума. При этом финансирование инвестиций в человеческий капитал имеет двуединую природу как процесс вложения финансовых средств и ресурсов и как инструмент инвестиционной деятельности. В самом общем плане все виды вложений в человека, которые могут быть оценены в денежной или иной форме и которые носят целесообразный характер, т.е. способствуют росту производительности труда и содействуют повышению доходов человека, - это инвестиции в человеческий капитал.

Инвестиции в человеческий капитал имеют специфические черты, вытекающие из его особенностей:

- доходность инвестиций в человеческий капитал прямо зависит от предстоящего срока службы. Этим объясняется, почему его формирование выгоднее осуществлять в начальный период жизни человека; 
- по существующим оценкам, вложения в человеческий капитал гораздо выгоднее «обычных» капиталовложений, но чем позже делаются вложения, например на более высоких ступенях образования, тем отдача оказывается ниже;

- далеко не все выгоды от инвестиций в человеческий капитал принимают денежную форму, а могут иметь экстернальные эффекты, по меньшей мере удваивающие экономический выигрыш;

- человеческий капитал подвержен износу с «обратным знаком», т.е. по мере использования его ценность и объем не убывают, а увеличиваются. Это происходит главным образом за счет накопления опыта: зрелый работник, как правило, производительнее новичка;

- по мере накопления человеческого капитала его доходность может возрастать, а не снижаться (как это характерно для физического капитала). Образование повышает эффективность человека не только в качестве работника, но и в качестве обучающегося, т.е. ускоряет и облегчает процесс дальнейшего накопления знаний и навыков;

- передача человеческого капитала может осуществляться неформальными путями, в процессе совместной деятельности его носителей (например, от работников более опытных и квалифицированных к менее квалифицированным);

- накопленный человеческий капитал выступает ключевым ресурсом при его воспроизводстве в следующем поколении (установлено, например, что уровень образования матери является важнейшим фактором, определяющим будущий уровень образования детей).

Спрос и предложение инвестиций в человеческий капитал формализованы Г. Беккером. Выведенная им индивидуальная кривая спроса на вложения в образование, показывающая уровень их отдачи, имеет отрицательный наклон, что объясняется следующими причинами [4]:

- длительное обучение часто сопровождается нарастанием интеллектуальных и физических нагрузок; чем больше индивид уже накопил человеческого капитала, тем дороже ему обходится потеря заработков в процессе обучения;

- поздние инвестиции приносят доход в течение более короткого периода;

- с увеличением объема вложений повышается степень риска.

Правда, существует и контртенденция, которая на определенном участке может даже менять наклон этой кривой на положительный, ведь полученное образование делает человека не только более эффективным работником, но и более эффективным учеником и, значит, может облегчать и ускорять накопление новых знаний и навыков. Чем человек одареннее, тем выше, при прочих равных условиях, располагается кривая спроса так как при тех же затратах он способен приобретать больший объем знаний.
Кривая предложения, показывающая, во что обходится финансирование дополнительной единицы человеческого капитала, имеет отрицательный наклон. Рациональный инвестор постепенно будет переходить от самых дешевых источников средств к более дорогостоящим - от средств родителей и родственников (процент по которым равен для него нулю) к льготным займам от колледжей и университетов и, наконец, к банковским ссудам или сокращению текущего потребления. Чем больше финансовые возможности учащегося или его семьи, тем ниже будет расположена кривая предложения.

Наличие высшего образования снижает риск бедности более чем в два раза. Результаты исследований $[5,6,8]$ показывают, что доходы семей, где у всех взрослых есть высшее образование, на $20 \%$ выше среднего уровня. Напротив, если в семье нет взрослых с высшим образованием, благосостояние семьи оказалось на четверть ниже среднего уровня.

Чаще всего уровень жизни и благосостояние измеряются денежными доходами, однако понятия «уровень жизни», «благосостояние» и «доходы» не тождественны. Все большее число ученых разделяют мнение, что оценки доходов или ВВП на душу не могут служить надежными показателями прогресса в области благосостояния.

Для России актуальность многокритериального подхода обусловлена также проблемами статистического учета доходов, в частности, наличием значительного неформального сектора. В итоге денежные доходы являются лишь косвенной и не всегда самой точной характеристикой благосостояния домохозяйств.

В статье «Уровень и качество жизни московских домохозяйств: объективные и субъективные оценки» Алина Пишняк и Дарья Попова [7] представили результаты исследования, в котором они скомбинировали несколько индикаторов, включающих не только учет доходов и потребления, но и социальное самочувствие домашних хозяйств:

- уровень и неравенство в распределении денежных доходов;

- бедность по доходам;

- бедность по потребительским лишениям;

- субъективные оценки бедности;

- субъективные оценки личного положения;

- обеспокоенность социально-экономическим положением и оценка социальной среды.

По данным [5], номинальный доход населения Москвы в 2014 г. вырос по отношению к 2013 г. на $4,4 \%$ (составил 104,4 \%). Но с учетом роста цен москвичи стали не богаче, а беднее - реальные доходы жителей столицы в 2014 г. составили $97,9 \%$ от уровня 2013 г. и 98,2 \% от уровня 2012 г. Падение доходов затронуло прежде всего средний класс - доходы первого квинтиля (20\% населения с самыми низкими доходами) в ре- 
Таблица 1. Средняя начисленная заработная плата работников по группам занятий и уровню образования за октябрь 2013 г. [6]

\begin{tabular}{|c|c|c|c|c|c|c|c|}
\hline \multirow[t]{3}{*}{ Категория работников } & \multicolumn{7}{|c|}{ Средняя заработная плата, руб. } \\
\hline & \multirow[t]{2}{*}{ Всего } & \multicolumn{6}{|c|}{ В том числе имеющих образование } \\
\hline & & $\begin{array}{c}\text { высшее } \\
\text { профес- } \\
\text { сиональное }\end{array}$ & $\begin{array}{c}\text { среднее } \\
\text { профес- } \\
\text { сиональное }\end{array}$ & $\begin{array}{c}\text { начальное } \\
\text { профес- } \\
\text { сиональное }\end{array}$ & $\begin{array}{c}\text { среднее } \\
\text { (полное) } \\
\text { общее }\end{array}$ & $\begin{array}{l}\text { основное } \\
\text { общее }\end{array}$ & $\begin{array}{l}\text { не имеют } \\
\text { основного } \\
\text { общего }\end{array}$ \\
\hline 1 & 2 & 3 & 4 & 5 & 6 & 7 & 8 \\
\hline Все работники & 28702 & 38233 & 23869 & 23926 & 22886 & 21622 & 19850 \\
\hline $\begin{array}{l}\text { Руководители учреждений, органи- } \\
\text { заций и предприятий и их струк- } \\
\text { турных подразделений (служб) }\end{array}$ & 52001 & 56498 & 36658 & 34916 & 31724 & 29475 & - \\
\hline $\begin{array}{l}\text { Специалисты высшего уровня ква- } \\
\text { лификации }\end{array}$ & 33005 & 34735 & 25114 & 26657 & 27957 & 26003 & 36000 \\
\hline $\begin{array}{l}\text { Специалисты в области естественных } \\
\text { и инженерных наук }\end{array}$ & 39403 & 41077 & 31367 & 32806 & 33834 & 29418 & 36000 \\
\hline $\begin{array}{l}\text { Специалисты в области биологиче- } \\
\text { ских, сельскохозяйственных наук и } \\
\text { здравоохранения }\end{array}$ & 34975 & 36790 & 22033 & 19159 & 13693 & 7451 & - \\
\hline Специалисты в области образования & 28039 & 28977 & 22854 & 22531 & 20379 & 14340 & - \\
\hline $\begin{array}{l}\text { Прочие специалисты высшего уровня } \\
\text { квалификации }\end{array}$ & 32333 & 35044 & 23969 & 26059 & 28368 & 29158 & - \\
\hline $\begin{array}{ccc}\text { Специалисты } & \text { среднего } & \text { уровня } \\
\text { квалификации } & & \end{array}$ & 25848 & 31554 & 23905 & 23536 & 21318 & 15431 & 14291 \\
\hline $\begin{array}{l}\text { Специалисты среднего уровня квали- } \\
\text { фикации физических и инженерных } \\
\text { направлений деятельности }\end{array}$ & 34670 & 42194 & 30527 & 30447 & 26209 & 22212 & 7894 \\
\hline $\begin{array}{l}\text { Специалисты среднего уровня квали- } \\
\text { фикации и вспомогательный персонал } \\
\text { естественных наук и здравоохранения }\end{array}$ & 23561 & 23175 & 23950 & 22193 & 16807 & 16969 & 8913 \\
\hline $\begin{array}{l}\text { Специалисты среднего уровня квали- } \\
\text { фикации в сфере образования }\end{array}$ & 22617 & 25976 & 20993 & 20716 & 12751 & 11371 & 12160 \\
\hline $\begin{array}{l}\text { Средний персонал в области финан- } \\
\text { сово-экономической, административ- } \\
\text { ной и социальной деятельности }\end{array}$ & 26373 & 31683 & 21336 & 22433 & 23548 & 17986 & 16326 \\
\hline $\begin{array}{l}\text { Служащие, занятые подготовкой } \\
\text { информации, оформлением доку- } \\
\text { ментации, учетом и обслуживанием }\end{array}$ & 18904 & 21846 & 18112 & 17520 & 17378 & 17085 & 17056 \\
\hline $\begin{array}{l}\text { Работники, занятые подготовкой ин- } \\
\text { формации, оформлением документа- } \\
\text { ции и учетом }\end{array}$ & 20109 & 22326 & 19109 & 19271 & 17863 & 18851 & 12445 \\
\hline Служащие сферы обслуживания & 17357 & 20649 & 16921 & 15813 & 17008 & 15684 & 18198 \\
\hline $\begin{array}{l}\text { Работники сферы обслуживания, } \\
\text { жилищно-коммунального хозяйст- } \\
\text { ва, торговли и родственных видов } \\
\text { деятельности }\end{array}$ & 18818 & 24794 & 18211 & 17909 & 18538 & 17984 & 17514 \\
\hline $\begin{array}{l}\text { Работники сферы индивидуальных } \\
\text { услуг и защиты граждан и собствен- } \\
\text { ности }\end{array}$ & 17748 & 25890 & 16780 & 16776 & 17578 & 16954 & 15085 \\
\hline Продавцы, демонстраторы одежды & 20482 & 24148 & 20501 & 19239 & 20237 & 19270 & 23018 \\
\hline $\begin{array}{ll}\text { Рабочие } & \text { жилищно-коммунального } \\
\text { хозяйства } & \\
\end{array}$ & 20833 & 22121 & 20235 & 21662 & 20301 & 20731 & 18219 \\
\hline $\begin{array}{l}\text { Рабочие кино- и телестудий и родст- } \\
\text { венных профессий }\end{array}$ & 21057 & 16031 & 23462 & 19320 & 21572 & 19009 & 12053 \\
\hline $\begin{array}{l}\text { Рабочие, занятые на рекламно- } \\
\text { оформительских и реставрационных } \\
\text { работах }\end{array}$ & 30087 & 28524 & 31153 & 26789 & 29330 & 42209 & - \\
\hline $\begin{array}{l}\text { Квалифицированные } \\
\text { сельского, лаботники } \\
\text { хозяйств, рыбоводства, охотничьего } \\
\text { ства }\end{array}$ & 16337 & 19279 & 16590 & 17376 & 15859 & 15834 & 15268 \\
\hline
\end{tabular}




\begin{tabular}{|c|c|c|c|c|c|c|c|}
\hline \multicolumn{8}{|c|}{ Продолжение табл. 1} \\
\hline 1 & 2 & 3 & 4 & 5 & 6 & 7 & 8 \\
\hline $\begin{array}{l}\text { Квалифицированные работники то- } \\
\text { варного сельскохозяйственного про- } \\
\text { изводства, лесного, охотничьего хоз-в, } \\
\text { рыболовства и рыбоводства, имеющие } \\
\text { рыночную ориентацию }\end{array}$ & 16337 & 19279 & 16590 & 17376 & 15859 & 15834 & 15268 \\
\hline 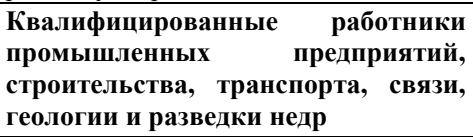 & 27943 & 30571 & 27742 & 27715 & 27741 & 27715 & 27549 \\
\hline $\begin{array}{l}\text { Рабочие, занятые на горных, горно- } \\
\text { капитальных и на строительно- } \\
\text { монтажных и ремонтно-строительных } \\
\text { работах }\end{array}$ & 28078 & 29399 & 27899 & 26950 & 28767 & 28808 & 26263 \\
\hline $\begin{array}{l}\text { Рабочие, металлообрабатывающей и } \\
\text { машиностроительной промышленно- } \\
\text { сти }\end{array}$ & 29395 & 32193 & 29010 & 29272 & 29057 & 29122 & 29918 \\
\hline $\begin{array}{l}\text { Рабочие, занятые изготовлением пре- } \\
\text { цизионных инструментов и приборов, } \\
\text { рабочие художественных промыслов, } \\
\text { рабочие полиграфического производ- } \\
\text { ства }\end{array}$ & 24725 & 25169 & 25826 & 25652 & 24068 & 21378 & 20332 \\
\hline $\begin{array}{l}\text { Другие профессии квалифицирован- } \\
\text { ных рабочих промышленных пред- } \\
\text { приятий }\end{array}$ & 21931 & 26082 & 21695 & 21331 & 22229 & 21339 & 19428 \\
\hline $\begin{array}{l}\text { Профессии рабочих транспорта и } \\
\text { связи (за исключением машинистов и } \\
\text { водителей) }\end{array}$ & 24608 & 26970 & 25567 & 25190 & 23317 & 21685 & 24077 \\
\hline $\begin{array}{l}\text { Операторы, аппаратчики, машини- } \\
\text { сты установок и машин }\end{array}$ & 27966 & 31150 & 26823 & 27730 & 28556 & 27091 & 25708 \\
\hline $\begin{array}{l}\text { Операторы, аппаратчики и машини- } \\
\text { сты промышленных установок }\end{array}$ & 29169 & 34256 & 28326 & 28708 & 29125 & 27399 & 25509 \\
\hline $\begin{array}{l}\text { Операторы, аппаратчики и машини- } \\
\text { сты и слесари-сборщики стационар- } \\
\text { ного оборудования }\end{array}$ & 23474 & 25898 & 23701 & 23261 & 22784 & 22533 & 22249 \\
\hline $\begin{array}{l}\text { Водители и машинисты подвижного } \\
\text { оборудования }\end{array}$ & 28990 & 32807 & 27443 & 28684 & 29934 & 28357 & 26840 \\
\hline Неквалифицированные рабочие & 13552 & 15294 & 13375 & 13720 & 13339 & 13660 & 12461 \\
\hline $\begin{array}{l}\text { Неквалифицированные рабочие сфе- } \\
\text { ры обслуживания, жилищно- } \\
\text { коммунального хозяйства, торговли и } \\
\text { родственных видов деятельности }\end{array}$ & 14064 & 15437 & 14503 & 13599 & 14123 & 13820 & 12749 \\
\hline $\begin{array}{l}\text { Неквалифицированные рабочие, сель- } \\
\text { ского, лесного, охотничьего хозяйств, } \\
\text { рыбоводства и рыболовства }\end{array}$ & 17363 & - & - & 8567 & 19571 & 27996 & 37153 \\
\hline $\begin{array}{l}\text { Неквалифицированные рабочие, заня- } \\
\text { тые в промышленности, строительст- } \\
\text { ве, на транспорте, в связи, геологии и } \\
\text { разведке недр }\end{array}$ & 21627 & 24512 & 20315 & 20182 & 20742 & 25844 & 19546 \\
\hline $\begin{array}{l}\text { Неквалифицированные рабочие, об- } \\
\text { щие для всех отраслей экономики }\end{array}$ & 13069 & 14748 & 12783 & 13488 & 12782 & 13096 & 12226 \\
\hline
\end{tabular}

альном выражении практически не изменились, а доходы представителей третьего квинтиля выросли на 9,2\%.

Средние душевые доходы домохозяйства зависят от демографической структуры семьи, концентрации индивидов с высшим образованием и количества занятых. Например, среднедушевые доходы семей с детьми в 1,6 раза ниже, чем у домохозяйств без детей. Также вероятность попадания в категорию бедных для семей с детьми в два раза выше, чем для бездетных домохозяйств в Москве и в 2,6 раза выше среднероссийской.
Наличие хотя бы одного члена семьи с высшим образованием снижает риск бедности в 2,3 раза. Доходы семей, где у всех взрослых есть высшее образование, на 20 \% выше среднемосковского уровня. Напротив, доходы семей, в которых нет взрослых с высшим образованием, ниже среднего уровня на четверть.

Впрочем, высшее образование - это еще не гарантия защиты от бедности. По данным [5], 8 \% «образованных» домохозяйств все же оказываются за чертой бедности, поскольку их члены заняты в бюджетном секторе.

Общепринятой практикой в европейских исследованиях является измерение бедности с по- 
Гарцуева Е.В.

Таблица 2. Отклонение средней заработной платы сотрудников, имеющих высшее профессиональное образование, от других уровней образования за октябрь 2013 г.

\begin{tabular}{|c|c|c|c|c|c|c|}
\hline \multirow[t]{2}{*}{ Категория работников } & \multicolumn{6}{|c|}{$\begin{array}{c}\text { Отклонение средней заработной платы сотрудников имеющих высшее } \\
\text { профессиональное образование, } \%\end{array}$} \\
\hline & всего & $\begin{array}{l}\text { среднее } \\
\text { профес- } \\
\text { сиональное }\end{array}$ & $\begin{array}{l}\text { начальное } \\
\text { профес- } \\
\text { сиональное }\end{array}$ & $\begin{array}{c}\text { среднее } \\
\text { (полное) } \\
\text { общее }\end{array}$ & $\begin{array}{l}\text { основное } \\
\text { общее }\end{array}$ & $\begin{array}{c}\text { не имеют } \\
\text { основного } \\
\text { общего }\end{array}$ \\
\hline 1 & 2 & 3 & 4 & 5 & 6 & 7 \\
\hline Все работники & 133 & 160 & 160 & 167 & 177 & 193 \\
\hline $\begin{array}{l}\text { Руководители учреждений, организаций и пред- } \\
\text { приятий и их структурных подразделений (служб) }\end{array}$ & 109 & 154 & 162 & 178 & 192 & \\
\hline Специалисты высшего уровня квалификации & 105 & 138 & 130 & 124 & 134 & 96 \\
\hline $\begin{array}{l}\text { Специалисты в области естественных и инженерных } \\
\text { наук }\end{array}$ & 104 & 131 & 125 & 121 & 140 & 114 \\
\hline $\begin{array}{l}\text { Специалисты в области биологических, сельскохозяй- } \\
\text { ственных наук и здравоохранения }\end{array}$ & 105 & 167 & 192 & 269 & 494 & \\
\hline Специалисты в области образования & 103 & 127 & 129 & 142 & 202 & \\
\hline Прочие специалисты высшего уровня квалификации & 108 & 146 & 134 & 124 & 120 & \\
\hline Специалисты среднего уровня квалификации & 122 & 132 & 134 & 148 & 204 & 221 \\
\hline $\begin{array}{l}\text { Специалисты среднего уровня квалификации физиче- } \\
\text { ских и инженерных направлений деятельности }\end{array}$ & 122 & 138 & 139 & 161 & 190 & 535 \\
\hline $\begin{array}{l}\text { Специалисты среднего уровня квалификации и вспо- } \\
\text { могательный персонал естественных наук и здраво- } \\
\text { oxранения }\end{array}$ & 98 & 97 & 104 & 138 & 137 & 260 \\
\hline $\begin{array}{l}\text { Специалисты среднего уровня квалификации в сфере } \\
\text { образования }\end{array}$ & 115 & 124 & 125 & 204 & 228 & 214 \\
\hline $\begin{array}{l}\text { Средний персонал в } \text { в области } \\
\text { экономической, административной и социальной дея- } \\
\text { тельности }\end{array}$ & 120 & 148 & 141 & 135 & 176 & 194 \\
\hline $\begin{array}{l}\text { Служащие, занятые подготовкой информации, } \\
\text { оформлением документации, учетом и обслужива- } \\
\text { нием }\end{array}$ & 116 & 121 & 125 & 126 & 128 & 128 \\
\hline $\begin{array}{l}\text { Работники, занятые подготовкой информации, оформ- } \\
\text { лением документации и учетом }\end{array}$ & 111 & 117 & 116 & 125 & 118 & 179 \\
\hline Служащие сферы обслуживания & 119 & 122 & 131 & 121 & 132 & 113 \\
\hline $\begin{array}{l}\text { Работники сферы обслуживания, жилищно- } \\
\text { коммунального хозяйства, торговли и родственных } \\
\text { видов деятельности }\end{array}$ & 132 & 136 & 138 & 134 & 138 & 142 \\
\hline $\begin{array}{l}\text { Работники сферы индивидуальных услуг и защиты } \\
\text { граждан и собственности }\end{array}$ & 146 & 154 & 154 & 147 & 153 & 172 \\
\hline Продавцы, демонстраторы одежды & 118 & 118 & 126 & 119 & 125 & 105 \\
\hline Рабочие жилищно-коммунального хозяйства & 106 & 109 & 102 & 109 & 107 & 121 \\
\hline Рабочие кино- и телестудий и родственных профессий & 76 & 68 & 83 & 74 & 84 & 133 \\
\hline $\begin{array}{l}\text { Рабочие, занятые на рекламно-оформительских и рес- } \\
\text { таврационных работах }\end{array}$ & 95 & 92 & 106 & 97 & 68 & \\
\hline $\begin{array}{l}\text { Квалифицированные работники сельского, лесно- } \\
\text { го, охотничьего хозяйств, рыбоводства и рыболов- } \\
\text { ства }\end{array}$ & 118 & 116 & 111 & 122 & 122 & 126 \\
\hline $\begin{array}{l}\text { Квалифицированные работники товарного сельско- } \\
\text { хозяйственного производства, лесного, охотничьего } \\
\text { хоз-в, рыболовства и рыбоводства, имеющие рыноч- } \\
\text { ную ориентацию }\end{array}$ & 118 & 116 & 111 & 122 & 122 & 126 \\
\hline $\begin{array}{l}\text { Квалифицированные работники промышленных } \\
\text { предприятий, строительства, транспорта, связи, } \\
\text { геологии и разведки недр }\end{array}$ & 109 & 110 & 110 & 110 & 110 & 111 \\
\hline $\begin{array}{l}\text { Рабочие, занятые на горных, горно-капитальных и на } \\
\text { строительно-монтажных и ремонтно-строительных } \\
\text { работах }\end{array}$ & 105 & 105 & 109 & 102 & 102 & 112 \\
\hline $\begin{array}{l}\text { Рабочие, металлообрабатывающей и машинострои- } \\
\text { тельной промышленности }\end{array}$ & 110 & 111 & 110 & 111 & 111 & 108 \\
\hline $\begin{array}{l}\text { Рабочие, занятые изготовлением прецизионных инст- } \\
\text { рументов и приборов, рабочие художественных про- } \\
\text { мыслов, рабочие полиграфического производства }\end{array}$ & 102 & 97 & 98 & 105 & 118 & 124 \\
\hline $\begin{array}{l}\text { Другие профессии квалифицированных рабочих про- } \\
\text { мышленных предприятий }\end{array}$ & 119 & 120 & 122 & 117 & 122 & 134 \\
\hline $\begin{array}{l}\text { Профессии рабочих транспорта и связи (за исключени- } \\
\text { ем машинистов и водителей) }\end{array}$ & 110 & 105 & 107 & 116 & 124 & 112 \\
\hline $\begin{array}{l}\text { Операторы, аппаратчики, машинисты установок и } \\
\text { машин }\end{array}$ & 111 & 116 & 112 & 109 & 115 & 121 \\
\hline
\end{tabular}




\begin{tabular}{|c|c|c|c|c|c|c|}
\hline & & & & & \multicolumn{2}{|c|}{ Продолжение табл. 2} \\
\hline 1 & 2 & 3 & 4 & 5 & 6 & 7 \\
\hline $\begin{array}{l}\text { Операторы, аппаратчики и машинисты промышленных } \\
\text { установок }\end{array}$ & 117 & 121 & 119 & 118 & 125 & 134 \\
\hline $\begin{array}{l}\text { Операторы, аппаратчики и машинисты и слесари- } \\
\text { сборщики стационарного оборудования }\end{array}$ & 110 & 109 & 111 & 114 & 115 & 116 \\
\hline Водители и машинисты подвижного оборудования & 113 & 120 & 114 & 110 & 116 & 122 \\
\hline Неквалифицированные рабочие & 113 & 114 & 111 & 115 & 112 & 123 \\
\hline $\begin{array}{l}\text { Неквалифицированные рабочие сферы обслуживания, } \\
\text { жилищно-коммунального хозяйства, торговли и родст- } \\
\text { венных видов деятельности }\end{array}$ & 110 & 106 & 114 & 109 & 112 & 121 \\
\hline $\begin{array}{l}\text { Неквалифицированные рабочие, сельского, лесного, } \\
\text { охотничьего хозяйств, рыбоводства и рыболовства }\end{array}$ & & & & & & \\
\hline $\begin{array}{l}\text { Неквалифицированные рабочие, занятые в промыш- } \\
\text { ленности, строительстве, на транспорте, в связи, геоло- } \\
\text { гии и разведке недр }\end{array}$ & 113 & 121 & 121 & 118 & 95 & 125 \\
\hline $\begin{array}{l}\text { Неквалифицированные рабочие, общие для всех отрас- } \\
\text { лей экономики }\end{array}$ & 113 & 115 & 109 & 115 & 113 & 121 \\
\hline
\end{tabular}

мощью метода относительных лишений (деприваций), когда домохозяйство не может позволить себе то или иное благо из-за нехватки средств.

Москвичам в 2014 г. чаще всего не хватало денег на оплату дорогостоящих медицинских услуг (63\% домохозяйств) и на крупные покупки $(58,8 \%)$.

Примерно четверть домохозяйств не могли заменить мебель и бытовые электроприборы, столько же было не в состоянии оплатить недельный отпуск вне дома.

Впрочем, это не самые серьезные лишения. По данным исследователей, почти у 16 \% домохозяйств недостаточно средств для недорогого профессионального образования, а 12,2 \% не в состоянии приглашать родственников и друзей на семейные праздники.

Значительное число семей (7-9 \%) не могут удовлетворить даже потребности базового уровня: потреблять фрукты и овощи в нужном количестве, оплатить покупку лекарств и медицинские услуги, обновить одежду и обувь и не реже чем через день есть мясо, курицу, рыбу.

Альтернативой абсолютному и относительному подходам к оценке бедности служит субъективная концепция бедности. По данным [5], представления о стандартах потребления меняются в зависимости от уровня доходов, демографического типа, уровня образования и занятости членов домохозяйства. Чем выше доходы, тем выше потребности. Так, для домохозяйств с доходами ниже прожиточного минимума субъективная черта бедности в 2014 г. проходила на уровне 17850 руб. на человека в месяц. Для домохозяйств с доходами в размере четырех и выше прожиточных минимумов уровень «выживания» составил 24630 руб. на человека в месяц.

Семьи, где есть хотя бы один взрослый с высшим образованием, указывают в 1,2 раза более высокий доход в качестве стандарта прожиточного минимума в сравнении с семьями, где ни у кого нет высшего образования.

В табл. 1, 2 представлены общероссийские показатели (раз в два года Федеральная служба государственной статистики на октябрь проводит исследование средней начисленной заработной платы работников по группам занятий и уровню образования), проанализировав которые, можно сказать, что в среднем по России специалист с высшим образованием в 1,3 раза имеет более высокий доход, а по отношению к другим уровням образования это более чем в 1,6 раза.

Подводя итог, можно сказать, что финансовая стратегия домохозяйств в инвестирование в свой человеческий капитал в настоящее время должна основываться на множестве факторов, главными из которых являются будущая сфера деятельности и возраст обучающегося.

\section{Литература}

1. Земиов А.А. Финансы домохозяйств. Ч. 1: Материалы к лекциям. Томск, 2008. $54 \mathrm{c}$.

2. Земиов А.А., Осипова Т.Ю. О структуре активов домашнего хозяйства // Вестник ТГУ. Экономика. 2011. № 1.

3. Земиов А.А. Домохозяйство: Основания. Финансы. Консалтинг. Томск: Изд. Дом Том. гос. ун-та, 2015. 352 с.

4. Беккер Г. Человеческий капитал (главы из книги). Воздействие на заработки инвестиций в человеческий капитал // США: экономика, политика, идеология. 1993. № 11. C. 109-119.

5. Мониторинг «Москва и москвичи» // http://igrm.info (дата обращения: 12.10 .2015 ).

6. Бюллетень о составе затрат организаций на рабочую силу в 2013 г. (опубликовано 01.10.2014 г.) // http:// www. gks.ru / free_doc/ 2014/trud/stv_zatrat_rs_\% 202 013. rar (дата обращения: 12.10 .2015$)$.

7. Пишняк А., Попова Д. Уровень и качество жизни московских домохозяйств: объективные и субъективные оценки // Журнал исследований социальной политики. 2014. Т.13., № 2. C. 257-272.

8. Овчарова Л.Н., Бурдяк А.Я., Пишняк А.И. и др. Динамика монетарных и немонетарных характеристик уровня жизни российских домохозяйств за годы постсоветского развития: аналитический доклад. М.: Фонд «Либеральная Миссия», 2014.

9. Becker G.S. Human Capital: A Theoretical and Empirical Analysis, with Special Reference to Education. Chicago: University of Chicago Press, 1964.

10. Stiglitz J., Sen A., Fitoussi J.P. Report by the Commission on the Measurement of Economic Performance and Social Progress. $2009 / / \mathrm{http} / / \mathrm{www} . u n . o r g / \mathrm{en} / \mathrm{ga} / \mathrm{president} / 65 /$ initiatives/ Harmony\%20with\%20Nature/Stiglitz-Sen-report-ENG.pdf (дата обращения: 12.10.2015). 